\title{
Testing our understanding of Arctic denitrification using MIPAS-E satellite measurements in winter 2002/2003
}

\author{
S. Davies ${ }^{1}$, G. W. Mann ${ }^{1}$, K. S. Carslaw ${ }^{1}$, M. P. Chipperfield ${ }^{1}$, J. J. Remedios ${ }^{2}$, G. Allen ${ }^{3}$, A. M. Waterfall ${ }^{4}$, R. Spang , $^{5}$, \\ and G. C. Toon ${ }^{6}$ \\ ${ }^{1}$ Institute for Atmospheric Science, School of Earth and Environment, University of Leeds, UK \\ ${ }^{2}$ Earth Observation Science, Space Research Centre, University of Leicester, UK \\ ${ }^{3}$ School of Earth, Atmospheric and Atmospheric Sciences, University of Manchester, UK \\ ${ }^{4}$ Rutherford Appleton Laboratory, Chilton, Didcot, UK \\ ${ }^{5}$ Institut 1: Stratosphare: Forschungszentrum Juelich, 52 425, Juelich, Germany \\ ${ }^{6}$ Jet Propulsion Laboratory, California Institute of Technology, Pasadena, California, USA
}

Received: 22 August 2005 - Published in Atmos. Chem. Phys. Discuss.: 1 November 2005

Revised: 13 June 2006 - Accepted: 21 July 2006 - Published: 31 July 2006

\begin{abstract}
Observations of gas-phase $\mathrm{HNO}_{3}$ and $\mathrm{N}_{2} \mathrm{O}$ in the polar stratosphere from the Michelson Interferometer for Passive Atmospheric Sounding aboard the ENVISAT satellite (MIPAS-E) were made during the cold Arctic winter of 2002/2003. Vortex temperatures were unusually low in early winter and remained favourable for polar stratospheric cloud formation and denitrification until mid-January. MIPAS-E observations provide the first dataset with sufficient coverage of the polar vortex in mid-winter which enables a reasonable estimate of the timing of onset and spatial distribution of denitrification of the Arctic lower stratosphere to be performed. We use the observations from MIPAS-E to test the evolution of denitrification in the DLAPSE (Denitrification by Lagrangian Particle Sedimentation) microphysical denitrification model coupled to the SLIMCAT chemical transport model. In addition, the predicted denitrification from a simple equilibrium nitric acid trihydrate-based scheme is also compared with MIPAS-E. Modelled denitrification is compared with in-vortex $\mathrm{NO}_{\mathrm{y}}$ and $\mathrm{N}_{2} \mathrm{O}$ observations from the balloon-borne MarkIV interferometer in mid-December. Denitrification was clearly observed by MIPAS-E in midDecember 2002 and reached $80 \%$ in the core of the vortex by early January 2003. The DLAPSE model is broadly able to capture both the timing of onset and the spatial distribution of the observed denitrification. A simple thermodynamic equilibrium scheme is able to reproduce the observed denitrification in the core of the vortex but overestimates denitrification closer to the vortex edge. This study also suggests that the onset of denitrification in simple thermodynamic schemes may be earlier than in the MIPAS-E observations.
\end{abstract}

Correspondence to: S. Davies

(stewart@env.leeds.ac.uk)

\section{Introduction}

The severity of seasonal halogen-catalysed ozone loss in the Arctic lower stratosphere is dependent on the prevailing meteorology. Sustained low temperatures are well known to promote the heterogeneous activation of halogen reservoirs via polar stratospheric clouds (PSCs). The predominant mechanism for the reverse process of sequestration of ozone-depleting active chlorine $\left(\mathrm{ClO}_{\mathrm{x}}=\mathrm{ClO}+2 \times \mathrm{Cl}_{2} \mathrm{O}_{2}\right)$ in the Arctic is via reaction with $\mathrm{NO}_{2}$ to form $\mathrm{ClONO}_{2}$. Hence a key aspect of activation balance is the availability of nitrogen species. Denitrification is the irreversible loss of total reactive nitrogen $\left(\mathrm{NO}_{\mathrm{y}}=\mathrm{N}+\mathrm{NO}+\mathrm{NO}_{2}+\mathrm{NO}_{3}+2 \mathrm{~N}_{2} \mathrm{O}_{5}\right.$ $+\mathrm{HNO}_{3}+\mathrm{ClONO}_{2}+$ minor species) from an airmass by the gravitational sedimentation of $\mathrm{NO}_{\mathrm{y}}$-containing particles. However, $\mathrm{HNO}_{3}$ is the main source of $\mathrm{NO}_{2}$ in the Arctic springtime vortex, produced either by photolysis or reaction with $\mathrm{OH}$, and its concentration is therefore particularly important. Several CTM studies have shown that denitrification in mid-winter can increase springtime Arctic ozone loss by reducing $\mathrm{HNO}_{3}$ concentrations in the lower stratosphere, thus reducing the rate of $\mathrm{ClO}_{x}$ deactivation and extending the ozone loss period (e.g. Chipperfield and Pyle, 1998; Waibel et al., 1999; Tabazadeh et al., 2000; Davies et al., 2002).

Moderate denitrification of the Arctic lower stratosphere has been observed in many cold winters of the late 1980s and 1990s (e.g. Fahey et al., 1990; Sugita et al., 1998; Kondo et al., 2000; Santee et al., 2000). In situ $\mathrm{NO}_{\mathrm{y}}$ observations from the NASA ER-2 during the cold Arctic winter of 1999/2000 revealed denitrification of an unprecedented magnitude (Popp et al., 2001). In addition to extensive denitrification, ER-2 flights in January and February 2000 revealed the presence of very large nitric acid trihydrate (NAT) particles (up to $20 \mu \mathrm{m}$ diameter) with very low concentrations

Published by Copernicus GmbH on behalf of the European Geosciences Union. 
(in the range $10^{-5}$ to $10^{-3} \mathrm{~cm}^{-3}$ ) in the Arctic lower stratosphere (Fahey et al., 2001). Subsequent modelling studies have indicated that the sedimentation of these large NAT particles was capable of causing denitrification comparable to that observed (Carslaw et al., 2002; Drdla et al., 2002). Mann et al. (2003) used the microphysical DLAPSE model to demonstrate that this mechanism may have caused denitrification in a number of other cold Arctic winters of the 1990s.

Davies et al. (2005) extended the work of Mann et al. (2003) by comparing the DLAPSE model against a wide range of observations from three Arctic winters (1999/2000, 1996/97 and 1994/95). They obtained good agreement by assuming a constant volume-average NAT nucleation rate. In two of these winters (1999/2000 and 1996/97), both the magnitude and spatial distribution of observed denitrification were reproduced by the model, within the constraints of the observations, when a particle nucleation rate derived from observed ER-2 NAT particle size distributions on 20 January 2000 (Northway et al., 2002) was used. However, it was not possible to deduce the onset of denitrification from observations in these winters. In the 1999/2000 Arctic winter, denitrification occurred between the deployment phases of the SOLVE/THESEO 2000 campaign (Newman et al., 2002) and was essentially complete by the time of the first ER-2 flight (Davies et al., 2005). In 1996/97, the Improved Limb Atmospheric Spectrometer (ILAS) satellite-borne instrument observed $\mathrm{HNO}_{3}$ and $\mathrm{N}_{2} \mathrm{O}$ during the onset of the low temperatures required for PSC formation and for potential denitrification (Kondo et al., 2000). However, the solar occultation technique used by ILAS restricted coverage in 1996/97 to a maximum of 14 northern hemisphere profiles per day in a narrow latitude band $\left(\sim 67^{\circ} \mathrm{N}\right.$ in February). The restricted view from ILAS means that the timing of denitrification inferred by ILAS measurements is likely to be controlled by a combination of denitrification and subsequent advection of denitrified airmasses to the ILAS occultation points (Davies et al., 2005).

Observations of nitric acid (but not $\mathrm{N}_{2} \mathrm{O}$ ) with greater spatial coverage but lower vertical resolution have been performed for a large number of years by the Microwave Limb Sounder (MLS) on the Upper Atmosphere Research Satellite (UARS). Santee et al. (1995) showed that the Antarctic experienced severe denitrification during the winter of 1992 whereas a similar decrease in $\mathrm{HNO}_{3}$ did not occur over the Arctic during the 1992/93 Arctic winter. Subsequent MLS observations for the 5 following Arctic and Antarctic winters demonstrated similar results (Santee et al., 1999). However, coverage is limited to 80 degrees in each hemisphere but in alternate yaw periods only ( $\sim 35$ days). Furthermore, the MLS data are limited by their precision, and the lack of coincident PSC and tracer information in most years. Most studies, e.g. Santee et al. (1999) have concentrated on the study of representative climatologies for $\mathrm{HNO}_{3}$ and other retrieved species.
Therefore, observations of $\mathrm{HNO}_{3}$ within the Arctic polar vortex in winters prior to 2002/2003 have been insufficient to accurately determine the timing of onset, the rate of progression and the spatial distribution of denitrification. These quantities are the key to confirming that the denitrification mechanism is realistically treated in large-scale models such as DLAPSE. For example, the onset of denitrification will differ between a model that assumes an ice or NAT-mediated mechanism. In addition, Mann et al. $(2002,2003)$ proposed that the duration that the vortex is near-concentric with the region of potential NAT formation controls the extent of denitrification by large NAT particles. They suggested that under some conditions denitrification can cease even when large regions of NAT exist. Such an effect might be detectable by examining the onset of denitrification in relation to the meteorological situation. Mann et al. (2002) also showed that denitrification by low concentrations of NAT would leave the vortex edge region weakly denitrified when compared with the core of the vortex. High-frequency, high spatial resolution observations of $\mathrm{HNO}_{3} / \mathrm{NO}_{\mathrm{y}}$ and $\mathrm{N}_{2} \mathrm{O}$ inside the polar vortex are required to address these issues.

The Michelson Interferometer for Passive Atmospheric Sounding on ENVISAT (MIPAS-E) provides, for Arctic winter 2002/2003, an excellent opportunity to study the issues identified above for denitrification. As described in Spang et al. (2005a), MIPAS-E provides daily observations with coverage of the vortex to the poles due to ENVISAT's sun synchronous orbit and adjustable line-of-sight views. In this paper, we use observations of $\mathrm{HNO}_{3}$ and $\mathrm{N}_{2} \mathrm{O}$ from MIPAS-E during the cold Arctic winter of 2002/3 to examine the onset and spatial distribution of denitrification and test the DLAPSE/SLIMCAT model. Comparisons are also made with the vertical distribution of $\mathrm{NO}_{\mathrm{y}}$ from the in-vortex MarkIV balloon flight in mid-December 2002. DLAPSE has a full microphysical treatment of NAT particle growth and sedimentation on a vortex-wide scale as described in Davies et al. (2005) and used by Mann et al. (2002). We also use the MIPAS-E observations to test whether the observed distribution of denitrification can be reproduced by a simple NAT equilibrium scheme, as used in many CTMs.

\section{Description of the MIPAS-E instrument and model}

\subsection{The MIPAS-E instrument}

MIPAS-E is a limb-scanning Fourier transform infra-red (FTIR) spectrophotometer aboard the ENVISAT satellite. ENVISAT orbits the Earth once every $\sim 100 \mathrm{~min}$, resulting in $\sim 14$ polar orbits per day. The IR emission from the Earth's atmosphere is sampled at $3 \mathrm{~km}$ intervals from 6 to $42 \mathrm{~km}$ (reduced sampling above), corresponding to the field-of-view and the nominal vertical resolution of the operationally retrieved data in the lower stratosphere. 
All MIPAS-E data used in the comparisons presented are based on level 2 products (V4.53-5) from the near real-time data produced by the European Space Agencys (ESA) operational processor. For $\mathrm{HNO}_{3}$ and $\mathrm{N}_{2} \mathrm{O}$ observations in polar regions, it has been estimated that the random errors are $<10 \%$ and $<20 \%$ respectively whilst systematic errors are estimated to be $<15 \%$ for each species (Oelhaf et al., 2004; Camy-Peyret et al., 2004). Systematic errors in $\mathrm{HNO}_{3}$ have a negligible effect on this study which concerns the relative changes of $\mathrm{HNO}_{3}$; subsequent to $\mathrm{V} 4.53$ a change in $\mathrm{HNO}_{3}$ spectroscopy (Flaud et al., 2003) results in a systematic increase of $14 \%$ in MIPAS $\mathrm{HNO}_{3}$ values. PSC particles may impact on the retrievals of both these species, therefore a cloud detection index (CI) for MIPAS-E, as described in Spang et al. (2005a), is used to remove MIPAS-E data whose quality may be affected by the presence of PSCs. A CIthreshold of 2.0 at any altitude between 12 and $31 \mathrm{~km}$ in a retrieval is used to reject such profiles (Spang et al., 1997; Spang and Remedios, 2003). An additional constraint is the removal of data for which substantial $\mathrm{HNO}_{3}$ uptake into PSCs may occur locally. We therefore restrict our analysis of MIPAS-E data to those profiles in which the ECMWFanalysed temperature is greater than $\mathrm{T}_{\mathrm{NAT}}-2 \mathrm{~K}$. Analysis of the model data suggests that the mean uptake of $\mathrm{HNO}_{3}$ into PSCs at MIPAS-E tangent points within the region $\mathrm{T}_{\mathrm{NAT}^{-}}$ $2 \mathrm{~K}<\mathrm{T}<\mathrm{T}_{\mathrm{NAT}}$ is $<0.7 \mathrm{ppbv}$ with an upper limit to the residual local uptake of $2.5 \mathrm{ppbv}$ at $465 \mathrm{~K}$ and $2 \mathrm{ppbv}$ at $505 \mathrm{~K}$ (Fig. 1). These results are consistent with tests of the dependence of the observed $\mathrm{HNO}_{3}$ data as a function of cloud index. In the model, condensed $\mathrm{HNO}_{3}$ is present predominantly as NAT rather than locally-sequestered super-cooled ternary solutions of $\mathrm{HNO}_{3}, \mathrm{H}_{2} \mathrm{SO}_{4}$ and $\mathrm{H}_{2} \mathrm{O}$ (STS).

Furthermore, we have examined the dependence of $\mathrm{HNO}_{3}$ anomalies (relative to a tracer correlation from early November) versus cloud index and find that for $\mathrm{CI}>2$ there is no evidence from the data for uptake of $\mathrm{HNO}_{3}$ into PSCs greater than $\sim 1$ ppbv which is broadly consistent with the model. These upper limits to the uptake should be compared to the strength of the denitrification signal which is of the order of 8 ppbv or more in late December and early January. In contrast, for $\mathrm{CI}<2.0$, we find significant anomalies indicative of uptake of $\mathrm{HNO}_{3}$.

\subsection{The DLAPSE/SLIMCAT model}

DLAPSE is a Lagrangian microphysical NAT particle model coupled to a full-chemistry version of the SLIMCAT CTM (Chipperfield, 1999). DLAPSE calculates the time dependent growth, advection and sedimentation of NAT particles and has been described in detail in Carslaw et al. (2002), Mann et al. (2003) and Davies et al. (2005). Changes in gas phase $\mathrm{HNO}_{3}$ due to growth of NAT particles are calculated by DLAPSE and are applied to the $\mathrm{HNO}_{3}$ field on the SLIMCAT grid, which is then advected in an Eulerian manner along with the other gas phase species. Both DLAPSE

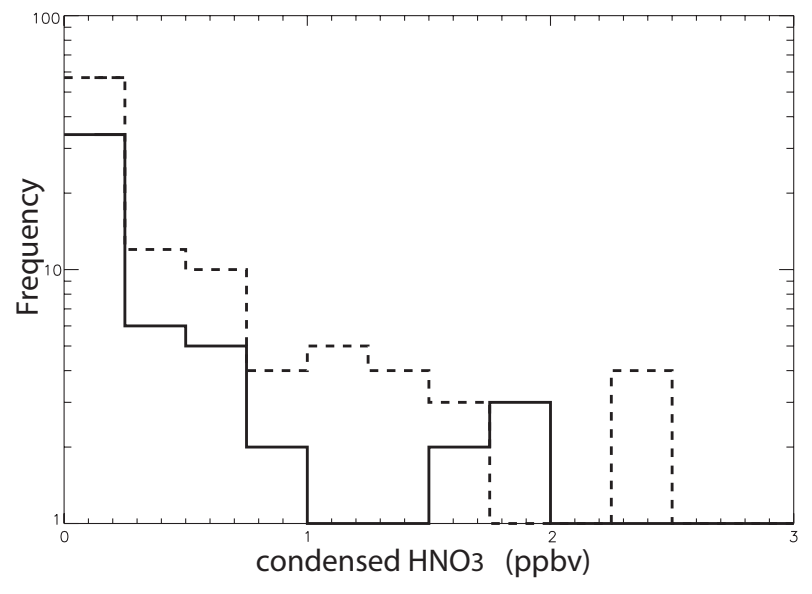

Fig. 1. Histograms of model NAT-phase $\mathrm{HNO}_{3}$ at MIPAS-E tangent points in the region $\mathrm{T}_{\mathrm{NAT}}-2 \mathrm{~K}<\mathrm{T}<\mathrm{T}_{\mathrm{NAT}}$ with $\mathrm{CI}>2.0$ at $505 \mathrm{~K}$ (solid line) and $465 \mathrm{~K}$ (dashed line).

and SLIMCAT are forced using operational analyses from the European Centre for Medium-Range Weather Forecasts (ECMWF). NAT particles are nucleated at a fixed rate wherever the temperature is below the NAT equilibrium temperature $\left(\mathrm{T}_{\mathrm{NAT}}\right.$ ) which is calculated from model $\mathrm{H}_{2} \mathrm{O}$ and $\mathrm{HNO}_{3}$ using Hanson and Mauersberger (1988). The uptake of $\mathrm{HNO}_{3}$ at low temperature into STS is also included in the model (Carslaw et al., 1995). Temporary uptake of $\mathrm{HNO}_{3}$ by STS reduces the amount of gas-phase $\mathrm{HNO}_{3}$ available for NAT particle growth.

For this study, the SLIMCAT resolution was $2.8^{\circ}$ longitude $\times 2.8^{\circ}$ latitude $\times 36$ isentropic levels. In the lower stratosphere, the model isentropic levels were spaced at $10 \mathrm{~K}$ potential temperature intervals, corresponding to a vertical resolution of around $400 \mathrm{~m}$. The SLIMCAT stratospheric chemistry scheme contains 41 species and $\sim 120$ chemical reactions, including heterogeneous reactions on STS, using data from Sander et al. (2000). Model tracers were initialised using values from a SLIMCAT multi-annual run (Chipperfield, 1999) on 7 November 2002, well before the onset of temperatures low enough to allow the formation of PSCs. To more accurately match the initial observed nitric acid field, the initial model $\mathrm{HNO}_{3}$ field was replaced by that observed by the MIPAS-E instrument on that day. For this purpose, the MIPAS-E observations were averaged onto a $20^{\circ}$ by $5^{\circ}$ longitude-latitude grid and then interpolated onto the model grid. An advantage of this approach is that the initialisation with MIPAS-E $\mathrm{HNO}_{3}$ implies that later comparisons are not sensitive to systematic errors in these observations. In effect, it is the relative change in MIPAS-E observations that are tested against the model denitrification. 
Table 1. Model sensitivity experiments. * indicates calculated by microphysical model.

\begin{tabular}{cccccc}
\hline Simulation & M0 & M1 & M2 & E1 & E2 \\
\hline Nucleation rate & 0.0 & 0.8 & 3.2 & - & - \\
$\left(10^{-9} \mathrm{~cm}^{-3} \mathrm{~s}^{-1}\right)$ & & & & & \\
Fall velocity $\left(\mathrm{ms}^{-1}\right)$ & $*$ & $*$ & $*$ & 0.005 & 0.001 \\
Equivalent radius $(\mu \mathrm{m})$ & $*$ & $*$ & $*$ & 3.0 & 1.2 \\
\hline
\end{tabular}

\subsection{Model simulations}

Three main simulations were undertaken: (M1) using DLAPSE with a low nucleation rate of $8.0 \times 10^{-10}$ particles $\mathrm{cm}^{-3} \mathrm{~s}^{-1}$; (M2) DLAPSE with a high nucleation rate of $3.2 \times 10^{-9}$ particles $\mathrm{cm}^{-3} \mathrm{~s}^{-1}$; and (M0) a "passive" run in which no NAT particles formed. The lower nucleation rate corresponds to that used in Mann et al. (2003), which was found by Davies (2003) to best fit nitric acid measurements aboard the ER-2 in winter 1999/2000. The higher nucleation run was found to better match denitrification profiles observed in the 1994/95 Arctic winter (Davies et al., 2005). Two further model runs (E1 and E2) were undertaken using an equilibrium denitrification scheme based on the sedimentation of large NAT particles within the SLIMCAT CTM. Here, the equilibrium amount of condensed $\mathrm{HNO}_{3}$ determined by Hanson and Mauersberger (1988) is sedimented with an assigned fall velocity. The fall velocities used for $\mathrm{E} 1$ and $\mathrm{E} 2$ were adjusted to produce denitrification values at $505 \mathrm{~K}$ in late-December which were approximately consistent with that provided by model runs M1 and M2 respectively. Note that the absolute denitrification is not what is being tested in this comparison, but only the spatial and temporal evolution. Table 1 summarises the model runs.

2.4 Determining and comparing observed MIPAS-E and modelled DLAPSE denitrification

Having performed calculations of denitrification, when the model is compared to the MIPAS-E data, account must be taken of the fact that the MIPAS-E data available for this study were $\mathrm{HNO}_{3}$ data, rather than $\mathrm{NO}_{\mathrm{y}}$, and that the retrieval is actually an average over a finite vertical distance. Throughout the period of this study (December 2002 - early January 2003), in-vortex $\mathrm{NO}_{\mathrm{y}}$ would be expected to be composed almost entirely of $\mathrm{HNO}_{3}$ as heterogeneous processing on PSCs would be expected to remove most of the $\mathrm{ClONO}_{2}$ and $\mathrm{N}_{2} \mathrm{O}_{5}$ due to the widespread low temperatures found within the vortex. In-vortex $\mathrm{HNO}_{3}$ photochemistry would also be expected to be slow. In the model, $\mathrm{HNO}_{3}$ comprises more than $90 \%$ of the available $\mathrm{NO}_{\mathrm{y}}$ throughout the December - January period with the remainder found to be predominantly $\mathrm{ClONO}_{2}(\sim 1 \mathrm{ppbv})$. Other $\mathrm{NO}_{\mathrm{y}}$ con-

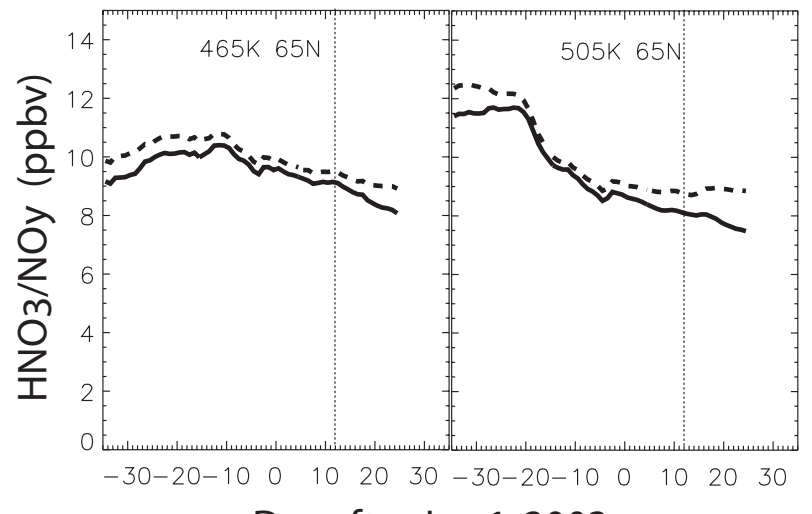

Day after Jan 1, 2003

Fig. 2. Timeseries of modelled vortex mean $\mathrm{HNO}_{3}$ (solid line) and $\mathrm{NO}_{\mathrm{y}}$ (dashed line) at $465 \mathrm{~K}$ and $505 \mathrm{~K}$. The edge of the vortex is defined as $65^{\circ} \mathrm{N}$ equivalent latitude.

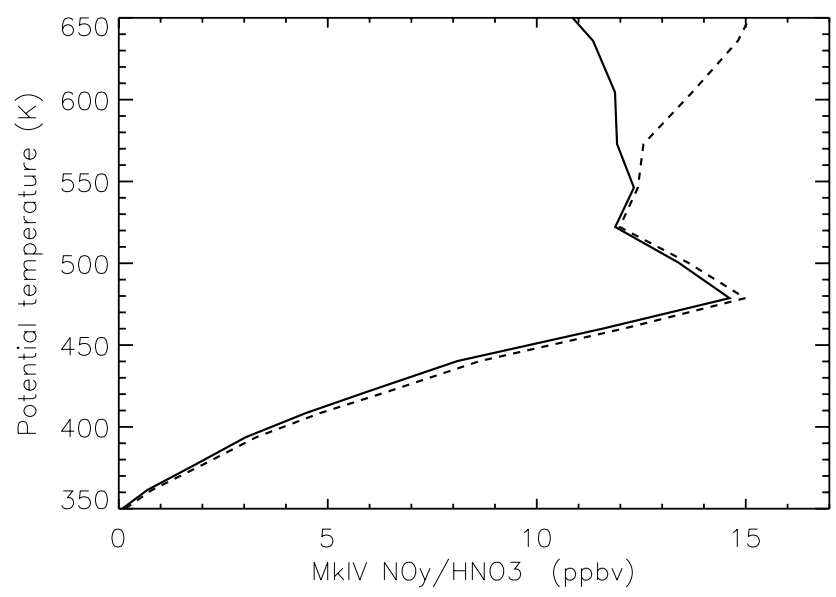

Fig. 3. Profiles of $\mathrm{HNO}_{3}$ (solid line) and $\mathrm{NO}_{\mathrm{y}}$ (dashed line) from the MarkIV balloon flight of 16 December 2002. The error bars have been omitted for clarity and are conservatively $<10 \%$ ( $\sim 0.5 \mathrm{ppbv}$ ) for the $400-600 \mathrm{~K}$ potential temperature range.

stituents are present at even lower abundances in the model $\left(\mathrm{NO}_{\mathrm{x}}<0.3 \mathrm{ppbv}\right.$ and $\left.\mathrm{N}_{2} \mathrm{O}_{5}<0.1 \mathrm{ppbv}\right)$ throughout this period. Figure 2 shows the discrepancy between modelled mean $\mathrm{HNO}_{3}$ and $\mathrm{NO}_{\mathrm{y}}$ at 465 and $505 \mathrm{~K}$ poleward of $65^{\circ} \mathrm{N}$ equivalent latitude to be $\leq 1 \mathrm{ppbv}$ throughout the December and early January period.

Independent observations of $\mathrm{NO}_{\mathrm{y}}$ partitioning in the midwinter Arctic vortex are sparse. The single in-vortex MarkIV balloon flight during this period demonstrates that $\mathrm{HNO}_{3}$ is an excellent proxy for $\mathrm{NO}_{\mathrm{y}}$ below $\sim 570 \mathrm{~K}$ (Fig. 3). We have restricted our analysis of MIPAS data to the period prior to the vortex split in mid-January as our assumptions about $\mathrm{NO}_{\mathrm{y}}$ partitioning are unlikely to be valid in a dynamically unstable vortex (Tsidu et al., 2005).

To determine an observed denitrification from the MIPASE measurements we use the MIPAS-E $\mathrm{N}_{2} \mathrm{O}$ and the relation 
of Popp et al. (2001) (derived for the 1999/2000 winter) to infer the deviation of $\mathrm{HNO}_{3}$ from the expected $\mathrm{NO}_{\mathrm{y}}$ value in the absence of any denitrification (referred to as $\mathrm{NO}_{\mathrm{y}}^{*}$ ). The modelled denitrification from DLAPSE is usually calculated as the difference between the nitric acid (or $\mathrm{NO}_{\mathrm{y}}$ ) concentration in a DLAPSE run and the corresponding passive run where the denitrification in the model has been switched off. However, since the MIPAS-E "denitrification" is defined as $\mathrm{HNO}_{3}-\mathrm{NO}_{\mathrm{y}}^{*}$, a proper comparison requires a matching definition of modelled DLAPSE "denitrification" as the difference between the $\mathrm{NO}_{\mathrm{y}}$ concentration in the passive run and the $\mathrm{HNO}_{3}$ concentration in the DLAPSE run. Throughout the remainder of this article we refer to denitrification observed by MIPAS-E as:

$\mathrm{HNO}_{3}-\mathrm{NO}_{\mathrm{y}}^{*}$,

with $\mathrm{NO}_{\mathrm{y}}^{*}$ determined from MIPAS-E $\mathrm{N}_{2} \mathrm{O}$. The comparable denitrification in the model is calculated as

$\mathrm{HNO}_{3}$ - passiveNO $\mathrm{N}_{\mathrm{y}}$

MIPAS-E does not retrieve the concentration from a single point. Instead the value of the retrieval represents a weighted average of concentrations over the $3 \mathrm{~km}$ vertical resolution of the instrument. Since the denitrification process can produce very steep vertical gradients, a direct comparison of the model with the observation at the retrieved potential temperature level is not appropriate. For a consistent comparison, the model denitrification profile must first have the observation averaging kernel applied. The averaging kernel for the MIPAS-E instrument is described in Carli et al. (2004) and is defined on a $1 \mathrm{~km}$ altitude grid. In all comparisons between MIPAS-E and DLAPSE, model profiles of $\mathrm{HNO}_{3}$ and passive $\mathrm{NO}_{\mathrm{y}}$ have been first linearly interpolated onto the $1 \mathrm{~km}$ altitude grid and then have had the MIPAS-E averaging kernel applied, leaving profiles on a $3 \mathrm{~km}$ altitude grid. These profiles were then linearly interpolated onto the isentropic levels $425 \mathrm{~K}, 465 \mathrm{~K}, 505 \mathrm{~K}$ and $545 \mathrm{~K}$. For the comparison on these levels, the MIPAS-E profiles were also linearly interpolated in potential temperature to give equivalent retrievals on these same potential temperatures surfaces.

\section{Evolution of Arctic denitrification in 2002/2003}

\subsection{Vortex meteorology}

The Arctic winter of 2002/2003 was colder than the climatological mean and characterised by an unusually early onset of temperatures sufficiently low for the existence of PSCs (Goutail et al., 2005). Spang et al. (2005b) report observations of PSCs as early as 1 December 2002. Larsen et al. (2004) report balloon-borne observations of PSCs at Esrange $\left(67.9^{\circ} \mathrm{N}, 21.1^{\circ} \mathrm{E}\right)$ and Sodankylä $\left(67.4^{\circ} \mathrm{N}, 26.6^{\circ} \mathrm{E}\right)$ between 3 December and 7 December 2002. PSCs were first observed at Ny Ålesund on 7 December 2002 although the tro-

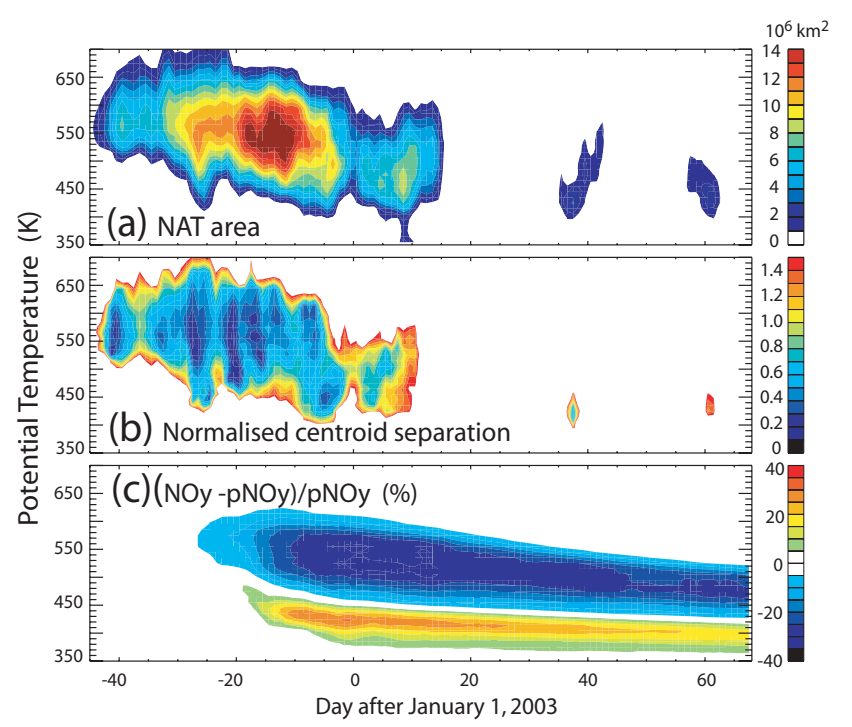

Fig. 4. (a) Model calculated NAT area $\left(10^{6} \mathrm{~km}^{2}\right)$ based on ECMWF analyses and $\mathrm{HNO}_{3}$ and $\mathrm{H}_{2} \mathrm{O}$ from model run M1; (b) Calculated normalised centroid separation (i.e. separation of the centroids of the polar vortex and NAT area, divided by NAT area); (c) Vortex mean $\mathrm{NO}_{\mathrm{y}}$ - passive $\mathrm{NO}_{\mathrm{y}}$ as a percentage of total passive $\mathrm{NO}_{\mathrm{y}}$ from run $\mathrm{M} 1$.

pospheric conditions were unsuitable for stratospheric viewing earlier in the winter.

Larsen et al. (2004) report that "small areas with temperatures below the NAT existence temperature $\mathrm{T}_{\mathrm{NAT}}$ started to develop on the $550 \mathrm{~K}$ potential temperature surface in midNovember". Figure 4a shows a time-potential temperature section of the area with temperatures below $\mathrm{T}_{\mathrm{NAT}}$ (the NAT area) using ECMWF analysed temperatures, model $\mathrm{HNO}_{3}$ and $\mathrm{H}_{2} \mathrm{O}$ and the expression of Hanson and Mauersberger (1988). The NAT area developed in mid November and by early December, the area of the vortex below $\mathrm{T}_{\mathrm{NAT}}$ (hereafter, the "cold pool") had increased significantly to cover an area of more than $10^{7} \mathrm{~km}^{2}$ throughout the region $525-575 \mathrm{~K}$ (see Fig. 4a). Figure $4 \mathrm{~b}$ shows the separation of the centre of the vortex and the centre of the cold pool and is a measure of the likely efficiency of denitrification (Mann et al., 2002). A value of zero indicates that the vortex and cold pool centres are co-located resulting in "cold closed flow", which is conducive to long NAT particle growth times and denitrification by large NAT particles (Mann et al., 2003). A value of 1 indicates that the centre of the cold pool is offset by its radius from the vortex and air flows through the cold pool before warming. Such through-flow conditions result in relatively short intermittent particle growth insufficient to produce large NAT particles. The cold pool had significant areas in closed flow for much of December, resulting in significant denitrification by NAT being predicted by DLAPSE. Figure $4 \mathrm{c}$ shows the model diagnosed vortex mean percent denitrification. Denitrification occurred in DLAPSE from 


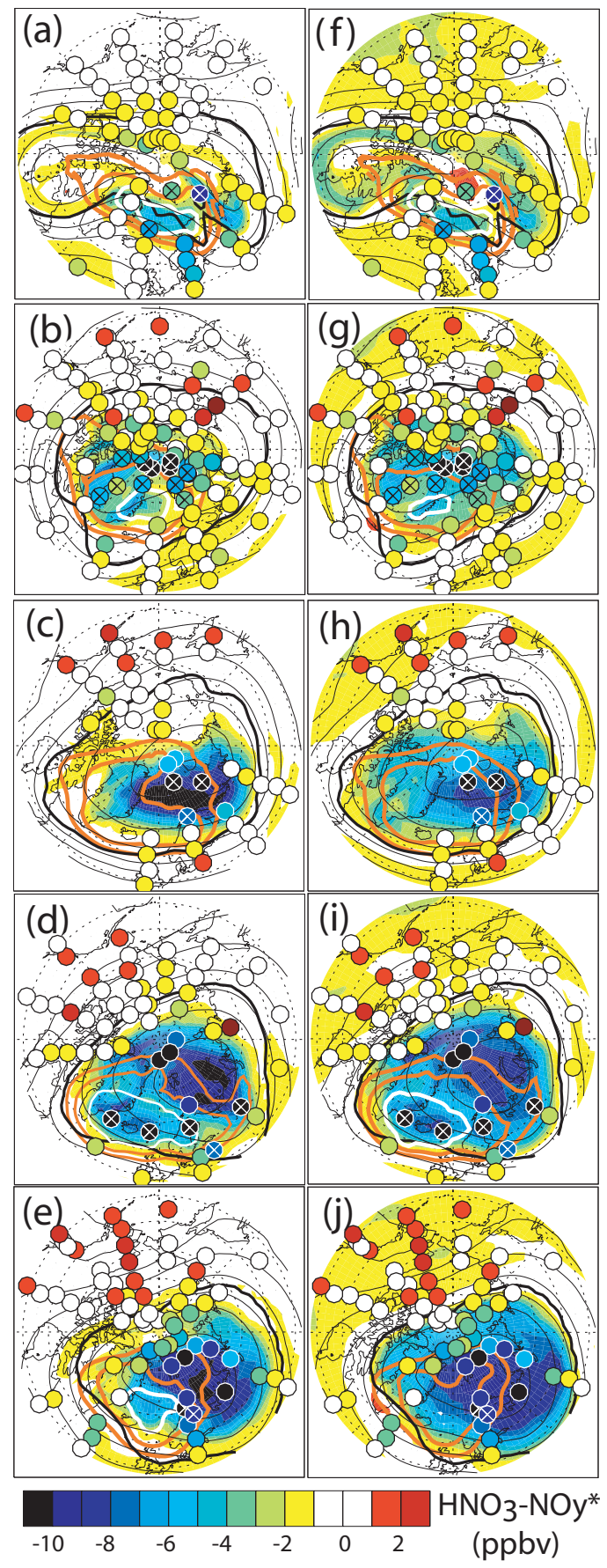

Fig. 5. Contour plot of model gas-phase $\mathrm{HNO}_{3}$ - passive $\mathrm{NO}_{y}$ for M2 (a-e: left) and E2 (f-j: right) at $505 \mathrm{~K}$ on 5 days in 2002: 9 , 13, 16, 19, 22 December. The magnitude of MIPAS-E $\mathrm{HNO}_{3}-\mathrm{NO}_{\mathrm{y}}^{*}$ is shown as filled circles. An $\mathrm{X}$ in a MIPAS-E observation indicates profiles where $2.0<\mathrm{CI}<2.5$ which may indicate the presence of PSCs (Spang et al., 2005a). Also shown are the $65^{\circ} \mathrm{N}$ Equivalent Latitude contour (thick black line), $\mathrm{T}_{\mathrm{NAT}}$ and $\mathrm{T}_{\mathrm{NAT}}-2 \mathrm{~K}$ (red lines), Montgomery streamfunction (thin black lines) and the region with $>1$ ppbv $\mathrm{HNO}_{3}$ uptake to liquid aerosol (white contour). early December, the timing being coincident with the time of maximum cold closed flow. According to the model, vortex mean denitrification reached a maximum of $\sim 35 \%$ at $520 \mathrm{~K}$ by 1 January 2003, after which the vortex warmed significantly.

In mid-January a sudden stratospheric warming increased temperatures above the threshold for PSC formation, displacing the vortex over central Europe. The polar vortex split on 20 January 2003 although the two vortex parts recombined a few days later. The recombined vortex cooled again in late January, by which time temperatures were infrequently low enough for the formation of PSCs. Further warmings occurred in mid February and early March. Sporadic PSCs were observed in February and March, usually associated with additional cooling from orographic temperature perturbations or tropospheric uplift (Naujokat and Grunow, 2003; Spang et al., 2005b). We restrict the analysis in this study to the period prior to the first warming in mid-January.

High resolution in situ $\mathrm{NO}_{\mathrm{y}}$ observations of the Arctic lower stratosphere by the SIOUX instrument aboard the Geophysica aircraft in January and February 2003 revealed significant renitrification between 400 and $440 \mathrm{~K}$, together with evidence of moderately strong denitrification at higher altitudes (Grooß et al., 2005).

\subsection{Evolution of model denitrification}

Figure 5 compares the evolution of modelled and MIPASE observed denitrification, with the observations shown as over-plotted coloured circles. Only points at equivalent latitudes greater than $65^{\circ} \mathrm{N}$ and having a $\mathrm{CI}>2.0$ are shown. Figures $5 \mathrm{a}$ to $5 \mathrm{e}$ correspond to model run M2 and Figs. 5f to $5 \mathrm{j}$ correspond to model run E2 for the days indicated. In each plot, contours of the Montgomery streamfunction indicate the direction of air flow. Figure 5a shows that on 9 December 2002 the Arctic vortex was elongated with two centres of flow. At this time, the cold pool was located close to the edge of the vortex, resulting in air mass trajectories with short durations below PSC temperatures. The orientation of the vortex and cold pool were similarly offset throughout the first week of December (not shown). According to the microphysical model, NAT particles formed in these cold air masses had insufficient time to grow appreciably, resulting in very weak denitrification despite the large region below $\mathrm{T}_{\mathrm{NAT}}$. In addition, analysed temperatures were extremely low in early December, resulting in sequestration of model gas-phase $\mathrm{HNO}_{3}$ in supercooled ternary solution particles (STS) and hence further restriction of NAT growth. At this time, the DLAPSE model run M2 predicts a peak denitrification of 3-4 ppbv in a narrow region over northern Russia. Denitrification calculated by equilibrium run E2 (Fig. 5f) shows broadly similar features to M2 although there is a more pronounced "tongue" of weakly denitrified air following the vortex flow across the pole from Arctic Russia to Canada. Particle sedimentation in the equilibrium model 
occurs at a fixed rate therefore any air mass that is exposed to temperatures below $\mathrm{T}_{\mathrm{NAT}}$ will undergo some denitrification.

From 13 December onwards, the vortex and cold pool centres become more closely aligned, creating a significant region of closed flow in the cold pool. Model denitrification in the core of the vortex (which corresponds to the region of cold closed flow) increased substantially over the following 10 days. Widespread MIPAS-E CI values below 2.0 close to the core of the vortex (Figs. 5b-d) also imply widespread PSC activity at this time. By 22 December, the vortex core was more than $80 \%$ denitrified in each model run. The discrepancies in the spatial distribution of denitrification between model runs M2 and E2 become more apparent from 16 December onwards (cf. Figs. 5c-e and Figs. 5h-j). Model run M2 has the region of denitrification closely constrained to the region of closed flow in the core of the vortex. In contrast, the denitrification in model run E2 is much more widely distributed, with high levels of denitrification even in the through-flow part of the cold pool. Observed denitrification (filled circles) by late December suggests that model run E2 significantly overestimates the spatial extent of denitrification at $505 \mathrm{~K}$. A more detailed comparison of the spatial distribution of denitrification from MIPAS-E and these model runs is discussed in Sect. 5.

A notable feature is that both model denitrification schemes have two centres of low gas phase $\mathrm{HNO}_{3}$ evident on 19 December 2002 (Figs. 5d and i). The large region of low $\mathrm{HNO}_{3}$ close to the centre of the vortex is most likely due to denitrification as temperatures are close to or just above $\mathrm{T}_{\mathrm{NAT}}$. MIPAS-E confirms the existence of strongly denitrified air in this region. The smaller region of low $\mathrm{HNO}_{3}$ over Iceland is most likely due to uptake into STS. MIPASE CI values below 2.5 for retrievals in this region indicate the likely presence of PSCs. (Differences in the uptake of $\mathrm{HNO}_{3}$ into STS between the model runs M2 and E2 are due to differing extents of denitrification in both models.)

As can be seen in Fig. 4a, in late December, the area of NAT supersaturation decreased significantly. This is partly caused by a minor stratospheric warming, but also the strong denitrification decreases $\mathrm{T}_{\mathrm{NAT}}$. Consequently model calculated denitrification was essentially complete by late December, irrespective of the scheme used (not shown).

It is also worth noting that MIPAS-E indicates regions of enhanced $\mathrm{HNO}_{3}$ relative to $\mathrm{NO}_{\mathrm{y}}^{*}$ at $505 \mathrm{~K}$ on 13 December (Figs. 5b, g) and from 19 December (Figs. 5d, i) as shown by red circles. It is possible that these are a signal of renitrification caused by the evaporation of NAT which has cocondensed onto ice particles which formed on the synoptic scale as temperatures were extremely low at $550 \mathrm{~K}$ in early December (Goutail et al., 2005).

\subsection{Comparison with MarkIV balloon}

The NASA Jet Propulsion Laboratory MarkIV balloon-borne interferometer flew from Esrange, near Kiruna $\left(67.9^{\circ} \mathrm{N}\right.$,

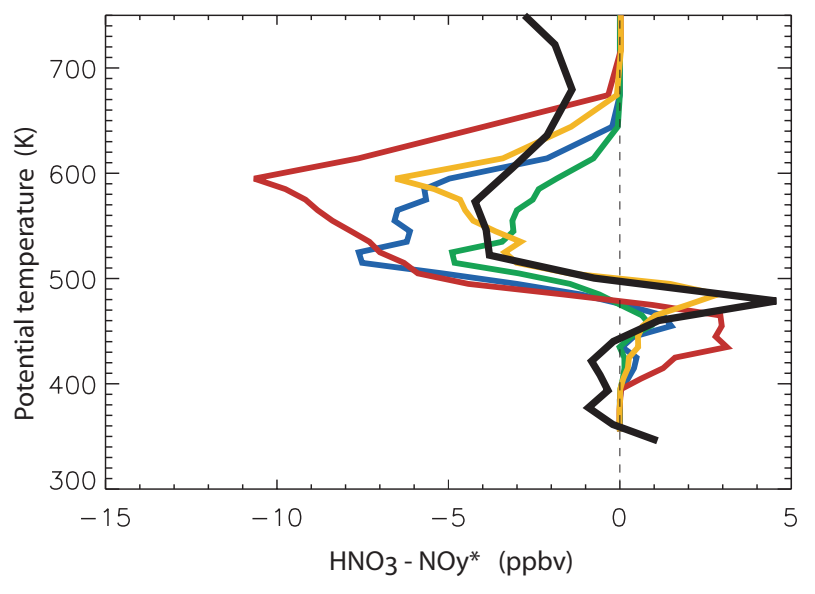

Fig. 6. Denitrification observed by the MarkIV balloon flight from Kiruna on 16 December 2002 (black). The model diagnosed denitrification interpolated to the location of the MarkIV from runs M1 (green), M2 (blue), E1 (orange) and E2 (red) are also shown. Denitrification from MarkIV is diagnosed as gas-phase $\mathrm{NO}_{\mathrm{y}}-\mathrm{NO}_{\mathrm{y}}^{*}$ and model denitrification is diagnosed from gas-phase $\mathrm{NO}_{\mathrm{y}}-$ passive $\mathrm{NO}_{\mathrm{y}}$ for all runs.

$21.1^{\circ} \mathrm{E}$ ) on 16 December 2002. Figures $5 \mathrm{c}$ and $\mathrm{h}$ show the model denitrification at $505 \mathrm{~K}$ on that day from model runs M2 and E2, respectively. According to the ECMWF analyses Northern Scandinavia was deep within the polar vortex and temperatures were $\sim 2 \mathrm{~K}$ below $\mathrm{T}_{\mathrm{NAT}}$. Model runs M2 and E2 both indicate significant ( 6 ppbv) denitrification above Kiruna at $505 \mathrm{~K}$ on this day although the region of strongest modelled denitrification ( $\sim 10 \mathrm{ppbv})$ was situated about $500 \mathrm{~km}$ northeast of Kiruna.

Figure 6 shows the denitrification profile as observed by the MarkIV interferometer and for the four model runs interpolated to the Esrange location. Since the MarkIV instrument measures most $\mathrm{NO}_{\mathrm{y}}$ species, here we compare the observed denitrification $\left(\mathrm{NO}_{\mathrm{y}}-\mathrm{NO}_{\mathrm{y}}^{*}\right)$ with the model denitrification $\left(\mathrm{NO}_{\mathrm{y}}-\right.$ passive $\left.\mathrm{NO}_{\mathrm{y}}\right)$ for each of the runs - M1, M2, E1, E2. Figure 6 shows that significant denitrification was observed by the MarkIV (black line) between $\sim 520$ and $\sim 600 \mathrm{~K}$. The observed denitrification does not tend to zero above $650 \mathrm{~K}$ because the $\mathrm{NO}_{\mathrm{y}}^{*}\left(\mathrm{~N}_{2} \mathrm{O}\right)$ relation from Popp et al. (2001) begins to break down for the low $\mathrm{N}_{2} \mathrm{O}$ concentrations at these altitudes. The two different model denitrification schemes predict two different shaped denitrification profiles. In the equilibrium model runs, peak denitrification occurs at a considerably higher altitude than in either of the two runs with the DLAPSE microphysical scheme. The peak denitrification in the equilibrium model scheme corresponds to the level where temperatures are furthest below $\mathrm{T}_{\mathrm{NAT}}$ whereas the microphysical scheme accounts for the variation in particles size with altitude leading to greater denitrification (larger particles) at lower levels. 


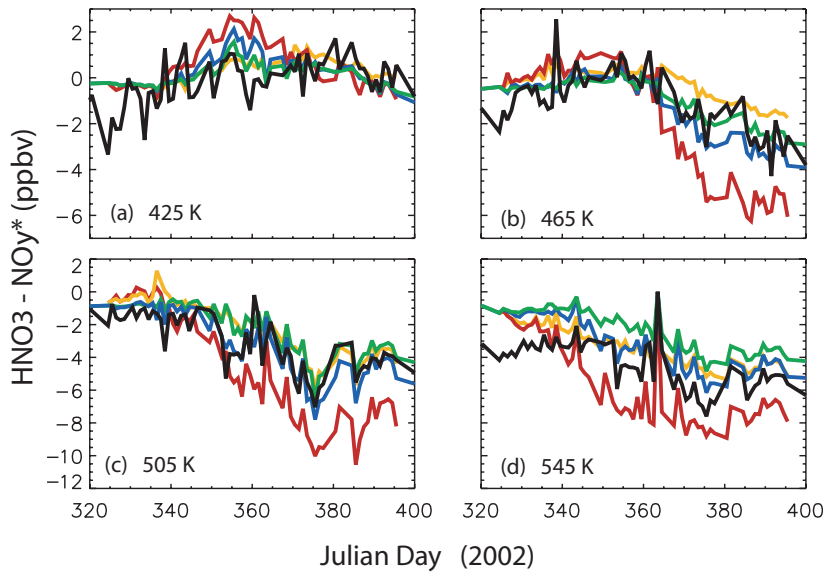

Fig. 7. Temporal evolution of 'average' MIPAS-E-observed (black line) and model denitrification poleward of $65^{\circ}$ Equivalent Latitude at 4 isentropic levels during 2002/3. Model diagnosed denitrification from runs, M1 (green) M2 (blue), E1 (orange) and E2 (red) are also shown. Model output is interpolated to the location of the MIPAS-E tangent points and similarly averaged. Denitrification is diagnosed as gas-phase $\mathrm{HNO}_{3}-\mathrm{NO}_{\mathrm{y}}^{*}$ for MIPAS-E and gas-phase $\mathrm{HNO}_{3}$ - passive $\mathrm{NO}_{\mathrm{y}}$ for model runs.

The shape of the observed denitrification profile is not reproduced at all altitudes by either of the model denitrification schemes. At high altitudes, denitrification is too strong in the equilibrium model runs, whereas the microphysical model runs tend to produce more denitrification than is observed at lower altitudes. Considering the microphysical model runs, at lower levels, the magnitude of observed denitrification from MarkIV is more consistent with that produced by the M1 run at the lower levels (around $500 \mathrm{~K}$ ). At higher altitudes however, the observed denitrification bridges that produced by model runs M1 and M2. A comparison of the magnitude of the observed denitrification with that produced by the equilibrium model runs shows that model E1 best matches the observed denitrification from MarkIV although both E1 and $\mathrm{E} 2$ significantly overestimate denitrification between 550 and $650 \mathrm{~K}$. Although the observed renitrification is best reproduced in run E2, this model run is incompatible with the observed denitrification. The Chemical Lagrangian Model of the Stratosphere (CLaMS) uses a denitrification scheme based on DLAPSE. CLaMS was able to broadly reproduce the renitrification observed by the MarkIV balloon (Grooß et al., 2005) which implies that the renitrification feature may be too small to be reproduced in SLIMCAT at the resolution used in this study. Minimum ECMWF-analysed temperatures were extremely low ( $\sim 181 \mathrm{~K}$ at $550 \mathrm{~K})$ in early December therefore it is also possible that ice PSCs may have been present (Goutail et al., 2005) and contributed to the denitrification observed by MarkIV.

\section{Timing of denitrification}

Observations of Arctic $\mathrm{NO}_{\mathrm{y}}$ species from a variety of platforms in a number of earlier winters have not been able to unambiguously determine the timing of the onset of stratospheric denitrification in the Arctic. The wide spatial coverage of MIPAS-E $\mathrm{HNO}_{3}$ and $\mathrm{N}_{2} \mathrm{O}$ provide an opportunity to determine both the onset and duration of denitrification in the Arctic during the winter of 2002/2003.

Figure 7 shows the evolution of denitrification inside the polar vortex as predicted by the four model runs on 4 isentropic levels $(425 \mathrm{~K}, 465 \mathrm{~K}, 505 \mathrm{~K}$ and $545 \mathrm{~K})$ and as measured by MIPAS-E. Section 2.4 describes the procedure used to enable the model and observations to be comparable on these levels. Each daily point in the graph approximates a "vortex average denitrification", which is the mean of observed or modelled denitrification interpolated to each of the valid retrieval points. Retrieval locations were assumed to be valid only if they satisfied all of the following criteria throughout the profile: MIPAS-E cloud index $>2.0$ (no interference from clouds; Spang et al., 2005a); ECMWF equivalent latitude $>65^{\circ}$ (inside the vortex); and $\mathrm{T}>\mathrm{T}_{\mathrm{NAT}}-2 \mathrm{~K}$ as determined from the ECMWF analyses, model $\mathrm{H}_{2} \mathrm{O}$ and $\mathrm{HNO}_{3}$ according to Hanson and Mauersberger (1988). The value of denitrification represented in Fig. 7 is not a true vortex average as MIPAS-E does not sample all equivalent latitudes equally, especially when the criteria detailed above are used. The noise in the signal of the denitrification is caused by this non-uniform sampling of the vortex.

Figure 5 shows that the first clear signal of denitrification at $505 \mathrm{~K}$ in MIPAS-E occurred on 19 December 2002 near the pole. Five of the observations on 19 December (shown as filled circles marked with an $\mathrm{X}$ ) may be weakly influenced by the presence of PSCs $(2.0<\mathrm{CI}<2.5)$, whilst three observations are clearly above $T_{\mathrm{NAT}}-2 \mathrm{~K}$. Consequently, only the latter points are within the criteria that we use to calculate the vortex average. The MIPAS-E $505 \mathrm{~K}$ denitrification (black line in Fig. 7c) for this day (plotted at Julian day 353.5) has negligible denitrification within the noise of the signal. There are indications that weak denitrification was observed by MIPAS-E on 16 December although these points are on the limit of the $\mathrm{T}_{\mathrm{NAT}}-2 \mathrm{~K}$ criterion we use to exclude possible uptake into PSCs. No MIPAS-E $\mathrm{HNO}_{3}$ data are currently available for 17-18 December.

The first point in Fig. 7c where the denitrification can be unambiguously determined to have begun is when denitrified air is advected out of the cold pool on 19 December (day 353.5) at $505 \mathrm{~K}$ and $545 \mathrm{~K}$. At $465 \mathrm{~K}$, the denitrification signal is much weaker and occurs later (day 370 onwards). Weak denitrification is preceeded by a slow increase in MIPAS-E $\mathrm{HNO}_{3}-\mathrm{NO}_{\mathrm{y}}^{*}$ which could be due to renitrification or heterogeneous conversion of $\mathrm{NO}_{\mathrm{y}}$ reservoirs to $\mathrm{HNO}_{3}$. A similar slow increase in $\mathrm{HNO}_{3}-\mathrm{NO}_{\mathrm{y}}^{*}$ is also observed at $425 \mathrm{~K}$ but no denitrification is evident. The relatively large offset between MIPAS-E $\mathrm{HNO}_{3}$ and $\mathrm{NO}_{\mathrm{y}}^{*}$ at 


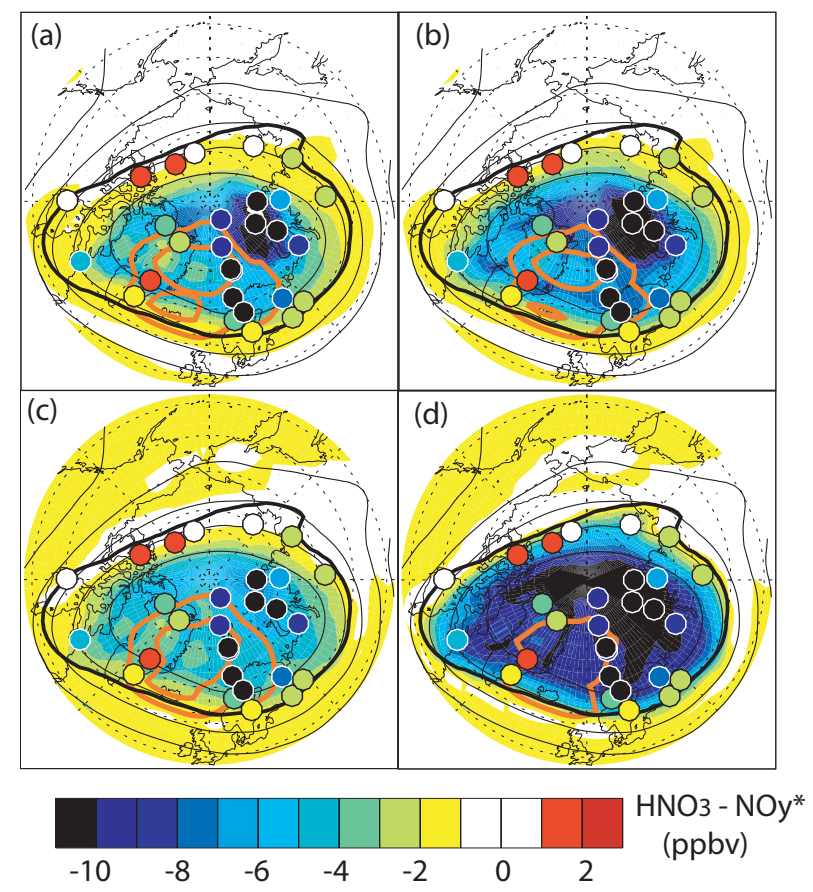

Fig. 8. Contour plots of $\mathrm{HNO}_{3}$ - passive $\mathrm{NO}_{\mathrm{y}}$ at $505 \mathrm{~K}$ on 3 January 2003 from model runs (a) M1, (b) M2, (c) E1 and (d) E2. MIPAS-E $\mathrm{HNO}_{3}-\mathrm{NO}_{\mathrm{y}}^{*}$ at tangent points are shown in filled circles.

$545 \mathrm{~K}$ makes detailed comparisons at this altitude more difficult.

The microphysical model runs M1 and M2 (green and blue respectively) capture the timing of denitrification well at all altitudes. This is especially true at $505 \mathrm{~K}$, where the initial offset between $\mathrm{HNO}_{3}$ and $\mathrm{NO}_{\mathrm{y}}^{*}$ is smaller. It is not clear which of the two NAT particle nucleation rates used in the model best match MIPAS-E observations. In contrast, the equilibrium model runs (E1 and E2) both have a relatively short period of weak renitrification followed by denitrification that does not agree with the MIPAS-E observations. The tendency for model runs E1 and E2 to denitrify too early is more pronounced at $545 \mathrm{~K}$. Denitrification begins around 10 days sooner in model runs E1 and E2 than is observed by MIPAS-E at this level. However, the 'vortex average' approach used here may mask some of the initial denitrification by cancellation of positive and negative signals. In addition, the exclusion of MIPAS-E profiles where PSCs may exist also limits the degree of certainty with which we can unambiguously determine the timing of denitrification from these observations. Although model run E1 could be considered to reproduce the temporal evolution of "average" denitrification observed by MIPAS-E, it significantly underestimates observed denitrification in the core of the vortex (Fig. 8).

In summary, the temporal evolution of model and MIPASE "vortex average" denitrification during the Arctic winter of 2002/2003 suggests that the microphysical scheme is

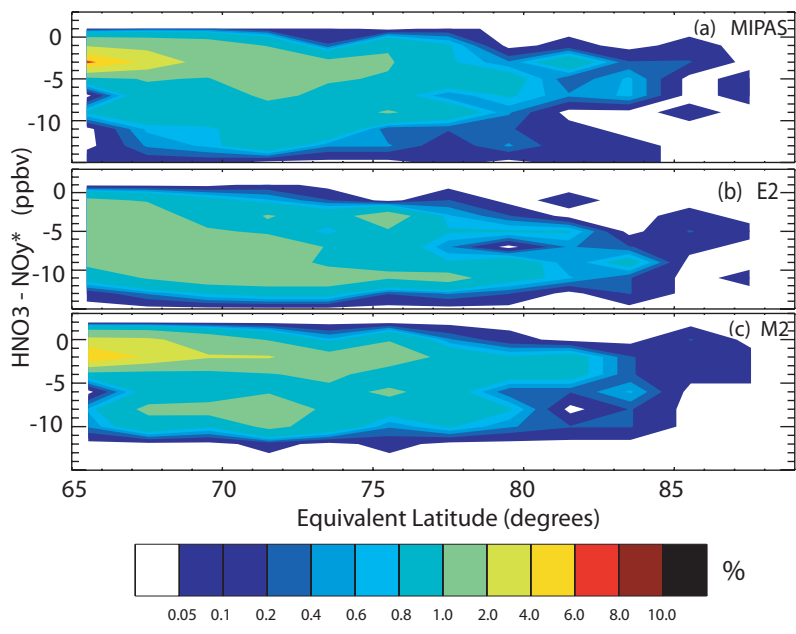

Fig. 9. Probability distribution of denitrification as a function of Equivalent Latitude at $505 \mathrm{~K}$ for (a) MIPAS-E observations, (b) model run E2 and, (c) model run M2 for the period 15 December 2002 to 12 January 2003. Model denitrification is interpolated to each MIPAS-E observation point. The bin size is $2^{\circ} \times 1 \mathrm{ppbv}$.

better able to reproduce the MIPAS-E observations. The best agreement between model and observation is obtained when the NAT nucleation rate is set to $3.2 \times 10^{-9} \mathrm{~cm}^{-3} \mathrm{~s}^{-1}$ as in the M2 run. The temporal change in denitrification in the equilibrium model run E2 (with particle fall speed chosen to approximately match the denitrification produced by M2 at $505 \mathrm{~K}$ ) does not match that of the MIPAS-E observations. Model run E1 produces "average" denitrification which more closely reproduces the MIPAS-E observations than model run E2 by producing denitrification of a lower magnitude over a wider area of the vortex than is observed but significantly underestimating the observed denitrification in the core of the vortex. The denitrification produced by the equilibrium scheme shows very different features than the MIPAS-E observations at higher altitudes.

\section{Spatial distribution of denitrification}

In this section the evolution of the spatial distribution of denitrification using the microphysical and equilibrium schemes is compared with observations from MIPAS-E. Figure 9 compares the modelled spatial distribution of denitrification in runs M2 and E2 with MIPAS-E at $505 \mathrm{~K}$ from midDecember to mid-January. The modelled distribution in run M2 agrees well with the observations (Fig. 9a). Both MIPAS-E observations and model run M2 demonstrate a bimodal distribution of denitrification at equivalent latitudes between 65 and $70^{\circ}$ with a high probability of little or no denitrification, together with a lower probability of strong denitrification $(\sim 8-9$ ppbv) in a narrow band. In contrast, model run E2 has an almost equal probability of denitrification from $\sim 0$ to $12 \mathrm{ppbv}$ in the 65 and $70^{\circ} \mathrm{N}$ equivalent 


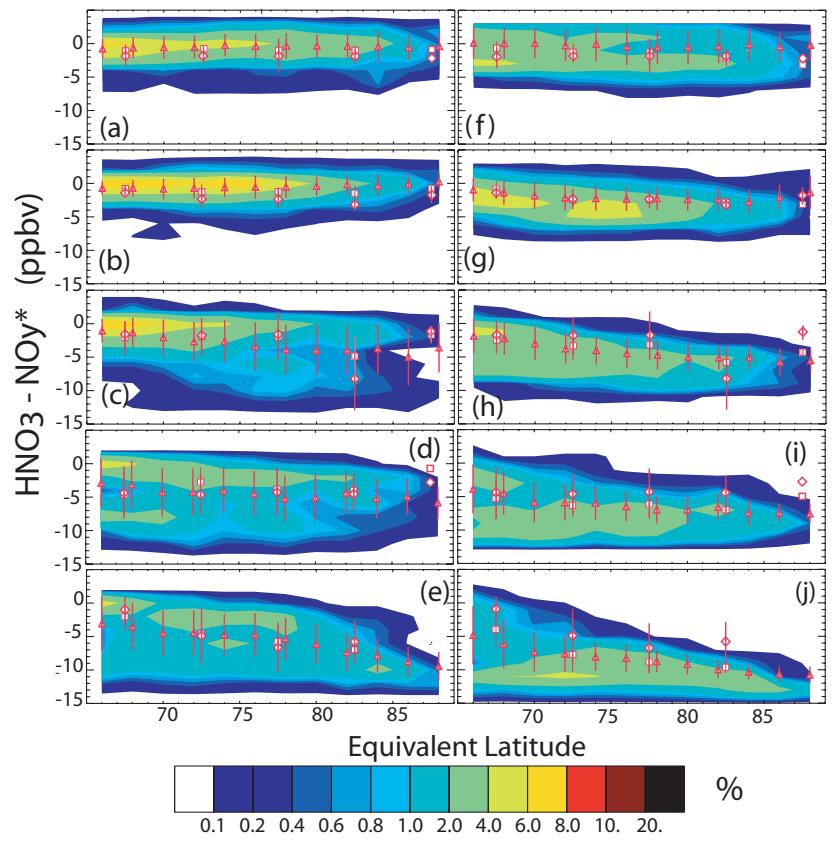

Fig. 10. Probability distribution of denitrification as a function of Equivalent Latitude at $505 \mathrm{~K}$ for seven 5 day periods from model run M2 (a-e: left) and model run E2 (f-j: right). From the top, the intervals are 2-6 December, 7-11 December, 12-16 December, 17-21 December and 27-31 December. Triangles show the modelled vortex mean denitrification at the indicated Equivalent Latitude. Squares indicate the MIPAS-E mean denitrification and diamonds indicate the vortex mean of model denitrification when interpolated to MIPAS-E.

latitude range. Both $\mathrm{M} 2$ and $\mathrm{E} 2$ produce a distribution of denitrification at equivalent latitudes above $75^{\circ} \mathrm{N}$ which is realistic when compared with MIPAS-E. The low probabilities at equivalent latitudes poleward of $80^{\circ} \mathrm{N}$ may be attributed to the low number of valid MIPAS-E points in that region during the period of study as many potentially denitrified profiles are excluded due to the presence of PSCs which affect the retrieval or temperatures below $\mathrm{T}_{\mathrm{NAT}}-2 \mathrm{~K}$ where significant $\mathrm{HNO}_{3}$ uptake cannot be excluded.

Figure 10 shows the distribution of modelled denitrification at $505 \mathrm{~K}$ from model runs M2 and E2 for five 5-day periods during December as a function of equivalent latitude. Model denitrification at each in-vortex grid point was placed into $1 \mathrm{ppbv} \times 2^{\circ}$ equivalent latitude bins. Triangles mark the mean and $1-\sigma$ standard deviation of the contoured model denitrification distribution. All in-vortex MIPAS-E points which satisfied the selection criteria described above were placed into $1 \mathrm{ppbv} \times 5^{\circ}$ equivalent latitude bins and plotted as squares. The diamonds represent the model interpolated to MIPAS-E observations and sampled similarly to MIPAS-E.

In the equilibrium run $\mathrm{E} 2$, denitrification occurs almost uniformly poleward of $\sim 67^{\circ} \mathrm{N}$ (Fig. $10 \mathrm{~h}-\mathrm{j}$ ) whereas the microphysical run M2 shows a higher incidence of denitrifica- tion at the higher equivalent latitudes (Fig. 10c-d). This feature of kinetically controlled denitrification is less apparent towards the end of December (Fig. 10e) when transport of denitrified air plays an increasing role in the spatial distribution of denitrification. Significant differences in the spatial distribution of denitrification between the two model runs remain, however. These differences are especially apparent towards the end of December (Figs. 10e and j). Both model runs have a relatively high occurrence of strong denitrification close to the centre of the vortex. However, the distribution of denitrification at lower equivalent latitudes within the vortex (between $\sim 70^{\circ}-80^{\circ} \mathrm{N}$ ) show significant differences.

In summary, the spatial distribution in the DLAPSE microphysical scheme agrees much better with observations than a model which simply assumes thermodynamic equilibrium between NAT and gas-phase $\mathrm{HNO}_{3}$. Out of the three comparisons performed here (timing, vertical distribution and horizontal distribution) it is the horizontal distribution of denitrification that provides the most compelling evidence that a microphysical scheme is more realistic than an equilibrium scheme.

\section{Conclusions}

The Arctic winter of 2002/2003 was unusually cold with temperatures below the PSC formation threshold from midNovember until mid-January. Denitrification of the Arctic lower stratosphere was observed by the JPL MarkIV interferometer over Scandinavia in mid-December 2002. $\mathrm{HNO}_{3}$ and $\mathrm{N}_{2} \mathrm{O}$ observations from the MIPAS-E instrument aboard ENVISAT were available throughout the polar vortex during this winter. MIPAS-E has provided an opportunity to examine the timing and spatial distribution of denitrification in this winter. We have used data from MIPAS-E to explore the temporal and spatial distribution of denitrification in the DLAPSE/SLIMCAT model. Comparisons were also made with a simple NAT-based equilibrium denitrification scheme.

Denitrification was first observed by MIPAS-E in midDecember between 505 and $545 \mathrm{~K}$. At these altitudes, the denitrification scheme in DLAPSE closely matched the timing of observed denitrification at these altitudes. In contrast, the simpler equilibrium denitrification scheme used in many CTMs tended to denitrify around 10 days too early when compared with MIPAS-E. This discrepancy was pronounced in the equilibrium model run with the higher denitrification rate but less evident when a lower denitrification rate was used. However, the equilibrium model run with the lower denitrification rate significantly underestimated the magnitude of denitrification in the core of the vortex. Early denitrification was especially pronounced at $545 \mathrm{~K}$, accompanied initially by weak renitrification at $505 \mathrm{~K}$. At lower altitudes (465 and $425 \mathrm{~K}$ ) where denitrification was weaker,the differences between model runs were less pronounced. The best fit to observations was achieved using the microphysical 
denitrification scheme with a nucleation rate of $3.2 \times 10^{-9}$ particles $\mathrm{cm}^{-3} \mathrm{~s}^{-1}$. The need for an increased NAT particle nucleation rate to match observations of denitrification during the Arctic winter of 2002/2003 is consistent with the results obtained by Grooß et al. (2005). They compared the denitrification produced from their DLAPSE-like scheme in the CLaMS model to MarkIV observations and later in situ observations from the Geophysica high altitude research aircraft.

Considerable differences in the spatial distribution of denitrification are apparent between microphysical and equilibrium denitrification schemes. Equilibrium denitrification schemes have been shown to denitrify over a wider horizontal area of the vortex than equivalent microphysical schemes in idealised simulations (Mann et al., 2002) when the relative orientation of the vortex flow and cold pool are offset. A baroclinic vortex is less favourable for denitrification by large NAT particles as the process requires particle trajectories to remain below $\mathrm{T}_{\mathrm{NAT}}$ for several days. The rate of denitrification increases non-linearly with time in microphysical growth models such as DLAPSE. Equilibrium schemes, however, generally denitrify at a fixed rate which is independent of the history of the air parcel. There were significant periods of time during the Arctic winter of 2002/2003 when the vortex and cold pool were offset, resulting in significant differences in the meridional distribution of denitrification between microphysical and equilibrium model runs. We have used the wide spatial coverage of MIPAS-E $\mathrm{HNO}_{3}$ and $\mathrm{N}_{2} \mathrm{O}$ to examine the horizontal distribution of model denitrification. These observations suggest that the equilibrium denitrification scheme used in this study overestimates the observed denitrification in the outer regions of the vortex (between $65^{\circ}$ and $70^{\circ} \mathrm{N}$ equivalent latitude) when the observed denitrification in the core of the vortex is reproduced. MIPAS-E observations indicate that the outer regions of the Arctic vortex were not significantly denitrified during the denitrifying phase throughout December and early January. The DLAPSE denitrification scheme reproduces the observed horizontal distribution of denitrification during this winter.

Equilibrium schemes tend to produce stronger denitrification than microphysical schemes at the highest altitudes ( $~ 550 \mathrm{~K}$ in $2002 / 2003)$ where mid-winter temperatures tend to be furthest below $\mathrm{T}_{\mathrm{NAT}}$. Denitrification at the highest altitudes in microphysical models is suppressed by the small size and slow uptake of $\mathrm{HNO}_{3}$ although quantification of this difference is beyond the scope of this study.

The present comparison with new satellite observations during winter 2002/2003, combined with the extensive comparison with in situ and remote observations from other winters (Davies et al., 2005), now provides strong support for the mechanism of denitrification in our 3-D model. Four clear statements about denitrification may now be made: 1) The onset and rate of Arctic denitrification can be explained by the formation, growth and sedimentation of NAT particles.
2) Synoptic-scale ice formation as a precursor to NAT formation cannot account for the observed development of Arctic denitrification, which occurs long before temperatures have fallen to the ice frost point (although this is not the case in 2002/2003). 3) The formation of NAT at a fixed nucleation rate uniformly throughout the NAT supersaturated region of the vortex produces 3-D fields of denitrification that agree well with extensive observations; none of the denitrification observations that we have analysed supports the need for a more complex NAT formation mechanism, although a single rate fails to reproduce the magnitude of denitrification equally well in all winters. 4) The co-location of the regions of low temperature and circulation is important in controlling the spatial distribution of denitrification, as originally suggested by Carslaw et al. (2002); Mann et al. (2002, 2003).

Acknowledgements. This work was supported by the European Commission Framework 5 projects EUPLEX and MAPSCORE projects under contracts EVK2-CT-2002-00084 and EVK2-CT2000-00072 and by the Framework 6 project SCOUT-O3. Work at the Jet Propulsion Laboratory was done under contract with the National Aeronautics and Space Administration.

Edited by: R. MacKenzie

\section{References}

Camy-Peyret, C., Dufour, G., Payan, S., Oelhaf, H., Wetzel, G., Stiller, G., Blumenstock, Th., Blom, C. E., Gulde, T., Glatthor, N., Engel, A., Pirre, M., Catoire, V., Moreau, G., De Mazière, M., Vigouroux, C., Mahieu, E., Cortesi, U., and Mencaraglia, F.: Validation of MIPAS $\mathrm{N}_{2} \mathrm{O}$ profiles by stratospheric balloon, aircraft and ground based measurements, Proc. ACVE-2 meeting, 3-7 May 2004, Frascati, Italy, 2004.

Carli, B., Alpaslan, D., Carlotti, M., et al.: First results of MIPAS/ENVISAT with operational level 2 code, Adv. Space Res., 33, 1012-1019, 2004.

Carslaw, K. S., Luo, B. P., and Peter, Th.: An analytic expression for the composition of aqueous $\mathrm{HNO}_{3}-\mathrm{H}_{2} \mathrm{SO}_{4}$ stratospheric aerosols including gas-phase removal of $\mathrm{HNO}_{3}$, Geophys. Res. Lett., 22, 1877-1880, 1995.

Carslaw, K. S., Peter, Th., Backmeister, J. T., and Eckermann, S. D.: Widespread solid particle formation by mountain waves in the Arctic stratosphere, J. Geophys. Res., 104, 1827-1836, 1999.

Carslaw, K. S., Kettleborough, J., Northway, M. J., Davies, S., Gao, R.-S., Fahey, D. W., Baumgardner, D. G., Chipperfield, M. P., and Kleinböhl, A.: A vortex-scale simulation of the growth and sedimentation of large nitric acid hydrate particles, J. Geophys. Res., 107(D20) 8300, doi:10.1029/2001JD000467, 2002.

Chipperfield, M. P. and Pyle, J. A.: Model sensitivity studies of Arctic ozone depletion , J. Geophys. Res., 103, 28 389-28 403, 1998.

Chipperfield, M. P.: Multiannual simulations with a three- dimensional chemical transport model, J. Geophys. Res., 104, 17811805, 1999.

Davies, S. Chipperfield, M. P., Carslaw, K. S., Sinnhuber, B.-M., Anderson, J. G., Stimpfle, R. M., Wilmouth, D. M., Fahey. D. W., Popp, P. J., Richard E. C., von der Gathen, P., Jost, H., and 
Webster, C. R.: Modeling the effect of denitrification on Arctic ozone depletion during winter 1999/2000, J. Geophys. Res., 107, 8322, doi:10.1029/2001JD000445, 2002.

Davies, S.: Denitrification and ozone loss in the Arctic stratosphere, $\mathrm{PhD}$ thesis, University of Leeds, UK, 2003.

Davies, S., Mann, G. W., Carslaw, K. S., Chipperfield, M. P., Kettleborough, J. A., Oelhaf, H., Wetzel, G., Santee, M. L., Sasano, Y., and Sugita, T.: 3-D microphysical model studies of Arctic denitrification: Comparison with observations, Atmos. Chem. Phys., 5, 3093-3109, 2005,

http://www.atmos-chem-phys.net/5/3093/2005/.

Drdla, K., Schoeberl, M. R., and Rosenfeld, J., Microphysical modeling of the 1999/2000 Arctic winter. 1. Polar stratospheric clouds, denitrification and dehydration, J. Geophys. Res., 108(D5), 8312, doi:10.1029/2001JD000782, 2002.

Fahey, D. W., Kelly, K. K., Kawa, S. R., et al.: Observations of denitrification and dehydration in the winter polar stratospheres, Nature, 344, 321-324, 1990.

Fahey, D. W., Gao, R.-S., Carslaw, K. S., et al.: The detection of large $\mathrm{HNO}_{3}$-containing particle in the winter Arctic stratosphere and their role in denitrification, Science, 291, 1026-1031, 2001.

Flaud, J.-M., Piccolo, C., Carli, B., Perrin, A., Coudert, L. H., Teffo, J.-L, and Brown, L. R.: Molecular line parameters for the MIPAS (Michelson Interferometer for Passive Atmospheric Sounding) experiment, J. Atmos. Ocean Optics, 16, 172-182, 2003

Fueglistaler, S., Luo, B. P., Voigt, C., Carslaw, K. S., and Peter, Th.: NAT-rock formation by mother clouds: a microphysical model study, Atmos. Chem. Phys., 2, 93-98, 2002,

http://www.atmos-chem-phys.net/2/93/2002/.

Goutail, F., Pommereau, J.-P., Lefèvre, F., et al.: Early unusual ozone loss during the Arctic winter 2002/2003 compared to other winters, Atmos. Chem. Phys., 5, 665-677, 2005,

http://www.atmos-chem-phys.net/5/665/2005/.

Groß, J.-U., Günther, G., Müller, R., Konopka, P., Bausch, S., Schlager, H., Voigt, C., Volk, C. M. and Toon, G. C., Simulation of denitrification and ozone loss for the Arctic winter 2002/3, Atmos. Chem. Phys., 5, 1437-1448, 2005,

http://www.atmos-chem-phys.net/5/1437/2005/.

Hanson, D. and Mauersberger, K.: Laboratory studies of nitric acid trihydrate: Implications for the south polar stratosphere, J. Geophys. Res., 101, 2117-2120, 1988.

Knopf, D. A., Koop, T., Luo, B. P., Weers, U. G., and Peter, Th.: Homogeneous nucleation of NAD and NAT in liquid stratospheric aerosols: insufficient to explain denitrification, Atmos. Chem. Phys., 2, 207-214, 2002,

http://www.atmos-chem-phys.net/2/207/2002/.

Kondo, Y., Irie, H., Koike, M., and Bodecker, G. E.: Denitrification and nitrification in the Arctic stratosphere during the winter of 1996/97, Geophys. Res. Lett., 27(3), 337-340, 2000.

Larsen, N., Knudsen, B. M., Svendsen, S. H., et al.: Formation of solid particles in synoptic-scale Arctic PSCs in early winter 2002/2003, Atmos. Chem. Phys., 4, 2001-2013, 2004, http://www.atmos-chem-phys.net/4/2001/2004/.

Mann, G. W., Davies, S., Carslaw, K. S., Chipperfield, M. P., and Kettleborough, J.: Polar vortex concentricity as a controlling factor in Arctic denitrification, J. Geophys. Res., 107(D22), 4663, doi:10.1029/2002JD002102, 2002.

Mann, G. W., Davies, S., Carslaw, K. S., and Chipperfield, M. P.: Factors controlling Arctic denitrification in cold winters of the 1990s, Atmos. Chem. Phys., 3, 403-416, 2003, http://www.atmos-chem-phys.net/3/403/2003/.

Meilinger, S. K., Koop, T., Luo, B. P., Huthwelker, T., Carslaw, K. S., Kreiger, U., Crutzen, P. J., and Peter, Th.: Size-dependent stratospheric droplet composition in mesoscale temperature fluctuations and their potential role in PSC freezing, Geophys. Res. Lett., 22, 3031-3034, 1995.

Müller, M., Neuber, R., Massoli, P., et al.: Differences in Arctic and Antarctic PSC occurrenceas observed by lidar in $\mathrm{Ny}$ Ålesund $\left(79^{\circ} \mathrm{N}, 12^{\circ} \mathrm{E}\right)$ and $\operatorname{McMurdo}\left(78^{\circ} \mathrm{S}, 167^{\circ} \mathrm{E}\right)$, Atmos. Chem. Phys., 5, 2081-2090, 2005,

http://www.atmos-chem-phys.net/5/2081/2005/.

Naujokat, B. and Grunow, K.: The stratospheric arctic winter 2002/3: Balloon flight planning by trajectory calculations, Proceedings of the 16th ESA Symposium on European Rocket and Balloon Programmes and Related Research, St. Gallen (ESA SP530), 421-425, 2003.

Newman, P. A. Harris, N. R. P., Adriani, A., et al.: An overview of the SOLVE/THESEO 2000 campaign, J. Geophys. Res., 107(D20), 8259, doi:10.1029/2001JD001303, 2002

Northway, M. J., Gao, R.-S., Popp, P. J., et al.: An analysis of large $\mathrm{HNO}_{3}$-containing particles sampled in the Arctic stratosphere during the winter of 1999/2000, J. Geophys. Res., 107(D20), 8298, doi:10.1029/2001JD001079, 2002.

Oelhaf, H., Blumenstock, T., De Mazière, M., Mikuteit, S., Vigouroux, C., Wood, S., Bianchini, G., Baumann, R., Blom, C., Cortesi, U., Liu, G. Y. , Schlager, H., Camy-Peyret, C., Catoire, V.,Pirre, M., Strong, K., and Wetzel, G.: Validation of MIPASENVISAT Version $4.61 \mathrm{HNO}_{3}$ operational data by stratospheric balloon, aircraft and ground-based measurements, Proceedings of ACVE-2 workshop, 3-7 May 2004, Frascati, Italy, 2004.

Popp, P., Northway, M. J., Holecek, J. C., et al.: Severe and extensive denitrification in the 1999-2000 Arctic winter stratosphere, Geophys. Res. Lett., 28, 2875-2878, 2001.

Sander, S. P., Ravishankara, A. R., Friedel, R. R., et al.: Chemical Kinetics and Photochemical Data for Use in Stratospheric Modeling, Evaluation 13, JPL Publ. 00-3, 2000.

Santee, M. L., Read, W. G., Waters, J. W., Froidevaux, L., Manney, G. L., Flower, D. A., Jarnot, R. F., Harwood, R. S., and Peckham, G. E.: Interhemispheric differences in polar stratospheric $\mathrm{HNO}_{3}$, $\mathrm{H}_{2} \mathrm{O}, \mathrm{ClO}$ and $\mathrm{O}_{3}$, Science, 267, 849-852, 1995.

Santee, M. L., Manney, G. L., Froidvaux, L., Read, W. G., and Waters, J. W.: Six years of UARS Microwave Limb Sounder $\mathrm{HNO}_{3}$ observations: Seasonal, interhemispheric, and interannual variations in the lower stratosphere, J. Geophys. Res., 104, 82258246, 1999.

Santee, M. L., Manney, G. L., Livsey, N. J., and Waters, J. W.: UARS Microwave Limb Sounder observations of denitrification ond ozone loss in the 2000 Arctic late winter, Geophys. Res. Lett., 27, 2313-2316., 2000.

Spang, R., Riese, M., and Offermann, D.: CFC 11 Measurements by CRISTA, Adv. Space Res., 19, 575-578, 1997.

Spang, R., Riese, M., and Offermann, D.: CRISTA-2 observations of the south polar vortex in winter 1997: A new dataset for polar process studies, Geophys. Res. Lett., 28, 3159-3162, 2001.

Spang, R. and Remedios, J. J.: Observations of a distinctive infrared spectral feature in the atmospheric spectra of polar stratospheric clouds measured by the CRISTA instrument, Geophys. Res. Lett., 30(16), 1875, doi:10.1029/2003GL017231, 2003. 
Spang, R., Remedios, J. J., Kramer, L. J., Fromm, M. D., Müller, M., Baumgarten, G., and Konopka, P., Polar stratospheric cloud onservations by MIPAS on ENVISAT: detection method, validation and analysis of the northern hemisphere winter 2002/3, Atmos. Chem. Phys. 5, 679-692, 2005a.

Spang R., Remedios, J. J., Tilmes, S., and Riese, M., MIPAS observation of polar stratospheric clouds in the Arctic 2002/3 and Antarctic 2003 winters, accepted for Adv. Space Res., 2005b.

Sugita, T., Kondo, Y., Nakajima, H., Schmidt, U., Engel, A., Oelhaf, H., Wetzel, G., Koike, M., and Newman, P. A.: Denitrification observed inside the Arctic vortex in February 1995, J. Geophys. Res., 103, 16 221-16223, 1998.

Tabazadeh, A., Santee, M. L., Danilin, M. Y., Pumphrey, H. C., Newman, P. A., Hamill, P. J., and Mergenthaler, J. L.: Quantififying denitrification and its effect on ozone recovery, Science, 288, 1407-1411, 2000.
Tabazadeh, A.: Role of the stratospheric polar freezing belt in denitrification, Science, 291, 2591-2594, 2001.

Tabazadeh, A., Djikaev, Y. S., Hammill, P., and Reiss, H.: Laboratory evidence for surface nucleation of solid polar stratospheric clouds, J. Phys. Chem A, 106(43), 10 238-10 246, 2002.

Tsidu, G. M., Stiller, G. P., von Clarmann, T., Funke, B., Fischer, H., Glatthor, N., Grabowski, U., Höpfner, M., Kellmann, S., Kiefer, M., Linden, A., Milz, M., Steck, T., and Wang, D. Y.: $\mathrm{NO}_{\mathrm{y}}$ from Michelson Interferometer for Passive Atmospheric Souding on Environmental Satellite during the southern hemisphere polar vortex split in September/October 2002, J. Geophys. Res., 110(D11), D11301, doi:10.1029/2004JD005322, 2005.

Waibel, A. E., Peter, T., Carslaw, K. S., Oelhaf, H., Wetzel, G., Crutzen, P. J., Poschl, U., Tsias, A., Reimer, E., and Fischer, H.: Arctic ozone loss due to denitrification, Science, 283, 2064 2069, 1999. 